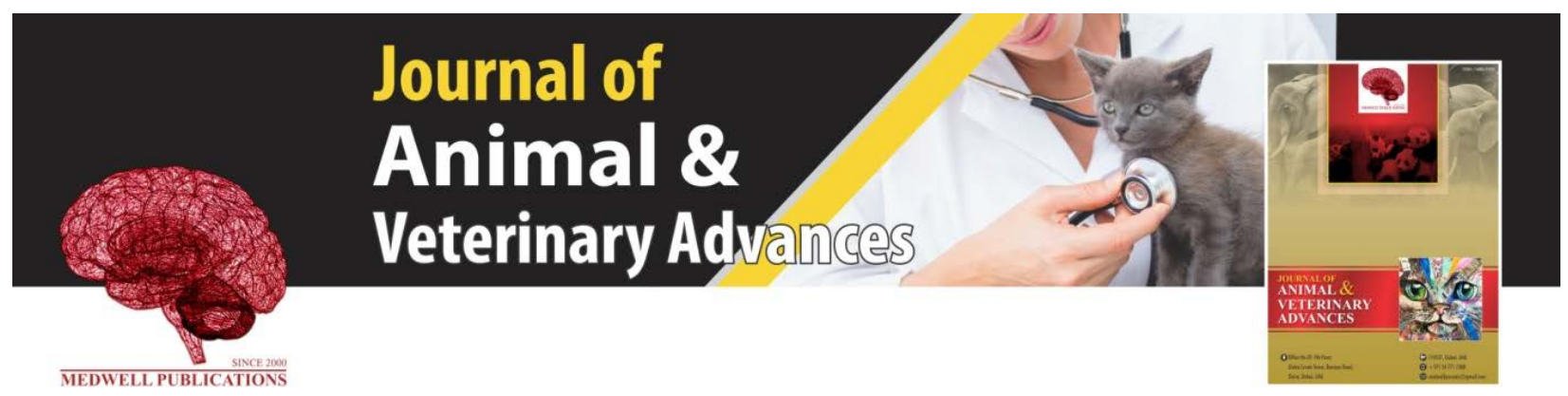

\title{
Chemical Composition, Vitamin and Fatty Acid Profile of Meat from Carcass Cuts of Indigenous Goat in Tunisian Arid Land
}

${ }^{1}$ Naziha Ayeb, ${ }^{1}$ Maha Hammouda, ${ }^{1}$ Mohamed Dbara, ${ }^{1}$ Mohamed Chniter, ${ }^{2}$ Belgacem Lachiheb, ${ }^{1}$ Mohamed Hammadi, ${ }^{1}$ Touhami Khorchani and ${ }^{1,3}$ Halima El-Hatmi

${ }^{1}$ Laboratory of Livestock and Wildlife,

${ }^{2}$ Laboratory of Arido-Culture and Oasis Culture, Institute of Arid Regions, Medenine, Tunisia

${ }^{3}$ Higher Institute of Applied Biology, Medenine, University of Gabes, Gabes, Tunisia

Key words: Carcass cuts, chemical composition, indigenous goat, fatty acid profile, local feeds resources

Corresponding Author:

Naziha Ayeb

Laboratory of Livestock and Wildlife, Institute of Arid Regions, Medenine, Tunisia

Page No.: 291-297

Volume: 18, Issue 10, 2019

ISSN: 1680-5593

Journal of Animal and Veterinary Advances

Copy Right: Medwell Publications
Abstract: The experiment was conducted to find out the nutritive value of different cuts of goat carcass. Ninety samples ( 6 cuts (shoulders, breasts, legs, rack, loin and necklaces $) \times 3$ diets $\times 5$ kids/diet) were used. Animals were divided according to 3 diets (SOL group: kids received Stipa tenacissima+olive leaves, $\mathrm{OH}$ : kids received oat hay and GH group: animals received grass hay). This research made to compare physicochemical quality and fatty acid of meat of cuts for kids feed by different diets. Results obtained showed that the chemical composition was not affected by the diet, exception to phosphorus which was higher in SO group (60.81 \pm 1.86$)$. On the contrary, exceptions to protein content, other physicochemical parameters have been varied between cuts. Colors were higher in the shoulders compared to other cuts. The diet did not affect fatty acid profile but was varied between cuts, especially, omega 3 and omega 6 which were higher in the legs followed by the rack. The different cuts were rich in vitamin $\mathrm{B}$; the breast was poorer in water-soluble vitamins.

\section{INTRODUCTION}

In Tunisia, livestock is the main activity considered as one of the most appropriate alternatives for the exploitation of arid environments with low agricultural potential. In Southern Tunisia, goat farming is directed mainly for the production of meat. Goat meat is one of the most widely eaten red meats in the Tunisian arid land, especially in Southern Tunisia. Goat meat is one of the most important protein sources for people living in rural areas and is a high-quality protein source. It is leaner than other red meats and its fat is less saturated than other ruminants (Ayeb et al., 2016). There is a high demand of goat meat in the market due to its palatability, less fat content, tenderness and good flavor. Feeding livestock is largely based on the use of natural rangelands that are rich in spontaneous species of variable nutritional value. Thus, other resources have been used such as: grass hay from various spontaneous species, the harvest of Stipa tenacissima and olive harvest residues (dried olive leaves, olive cake...) (Ayeb et al., 2014). These resources are able to meet some of the livestock's feed needs for most of the year. Indeed, it is interesting to study the effect of some local feed resources on the nutritional quality of meat. Several studies have been carried out to characterize carcass traits of goat kids and their 
crossbreeds with milking breeds under intensive or semi-intensive systems and different diet. However, there is limited information related to carcass characteristics of indigenous goat kids at different diets and related to characteristic of different cuts in Southern Tunisia. In this context, this experiment was carried out to have an idea on the attributes of various cuts of goat carcass. The objectives was aims to determine the effect of some food resources of Southern Tunisia; Stipa tenacissima, olive leaves and grass hay compared to oat hay on the physicochemical, biochemical and microbiological quality of the meat of the different cuts of the goat carcass.

Practical applications: Valorizing local resouces in animal feed is a traditional practice in arid regions but its effects on the quality of animal products are rarely studied. Its socio-economic impact is significant, since, it contributes to job creation through the sale of local resources to livestock farmers, it is an income supplement, so, much expected by farmers.

\section{MATERIALS AND METHODS}

The present study was conducted at the experimental station of the Arid Regions Institute (Medenine, Tunisia)

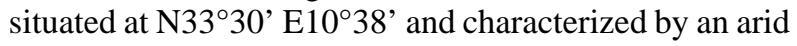
bioclimatic stage with an annual average rainfall of $180 \mathrm{~mm}$.

Animal and diet: Fifteen kids of goat's local population in Southern Tunisian were reared in individual pens. These animals were divided in three groups (body weight $=15.85 \mathrm{~kg}$; age $=4$ months) and used during 90 days. Each group was randomly assigned to ad libitum one of the three alimentary treatments: group control received oat hay (Group C), group GH received mixed grass hay and group OL received Stipa tenacissima+dried olive leaves. In all groups, kids were supplemented with a commercial concentrate and received water twice a day. The S. tenacissima was hand-harvested on native rangelands from the neighbouring Benikadeche mountains (South-East Tunisia) during the late growing period (April), air-dried, stocked in a dry area. Grass hay was composed from 16 annual and perennial species, the Specific Contribution (SC) was $44 \%$ for Launaea residifola; $30 \%$ for Lolium multiflorum $6.60 \%$ for Chrysanthemum coronarium; $4.12 \%$ for Anacyclis cyrtoploides and other species. Dried olive leaves are supplied from the neighbouring private farmers. Composition of the experimental feed is reported in Table 1.

Slaughter and samples collection: All kids were slaughter in the morning between 9:00 and 10:00 h. Before slaughter, kid's goats Body Weights (BW) were recorded. The carcasses were stored at $4^{\circ} \mathrm{C}$ for $24 \mathrm{~h}$ and
Table 1: Chemical composition and fatty acids of feeds used in the experiment period

\begin{tabular}{|c|c|c|c|c|}
\hline Samples & $\mathrm{OH}$ & ST & $\mathrm{OL}$ & $\mathrm{GH}$ \\
\hline \multicolumn{5}{|c|}{ Chemical composition (\%) } \\
\hline DM & 89.35 & 92.87 & 92.33 & 86.63 \\
\hline Ash & 3.09 & 4.91 & 8.74 & 7.99 \\
\hline СР & 6.34 & 6.33 & 10.16 & 9.44 \\
\hline $\mathrm{NDF}_{\mathrm{om}}$ & 60.06 & 85.00 & 34.59 & 42.18 \\
\hline $\mathrm{ADF}_{\mathrm{om}}$ & 42.72 & 55.51 & 30.35 & 29.32 \\
\hline \multicolumn{5}{|c|}{ Fatty acids (\%) } \\
\hline C16:0 & 30.35 & 20.48 & 32.98 & 26.68 \\
\hline C18:0 & 5.47 & 6.08 & 6.43 & 4.09 \\
\hline C18:1 & 15.68 & 5.42 & 16.01 & 5.38 \\
\hline C18:2 & 21.00 & 11.2 & 9.84 & 20.50 \\
\hline C18:3 & 12.51 & 10.25 & 12.49 & 24.33 \\
\hline SFA & 45.99 & 67.09 & 57.18 & 44.65 \\
\hline MUFA & 17.50 & 6.96 & 18.1 & 7.64 \\
\hline PUFA & 36.52 & 25.95 & 24.72 & 47.71 \\
\hline
\end{tabular}

DM: Dry Matter; CP: Crude Protein; NDF: Neutral Detergent Fibre; ADF: Acid Detergent Fiber; SFA: Saturated Fatty Acids; MUFA: Monounsaturated Fatty Acids; PUFA: Polyunsaturated Fatty Acids; OH: Oat Hay; ST: Stipa tenacissima L; OL: Dried Olive Leaves; GH: Grass Hay

then weighed. The tail was then removed and each carcass was split along the vertebral column mid line in two halves. The left half-carcass was cut into six joints according the procedures of Colomer-Rocher et al. (1987), every joint was weighed and dissected in fat, muscles and bones. After cutting, 90 samples (6 cuts of each animal (shoulders, breasts, legs, rack, loin and necklaces) of each animal $\times 5$ animals $\times 3$ diets $=90$ ) were studied in this research.

Physico-chemical analysis of meat: The $\mathrm{pH}$ value was determined at room temperature $\left(20^{\circ} \mathrm{C}\right)$ using an inoLab $\mathrm{pH}$ with $\mathrm{pH}$-meter (inoLab, Weilheim, Germany) after calibrating with two buffers (7.00 and 4.01). For chemical composition, samples of meat is chopped, homogenized and analyzed according to AOAC. (1990). Cooking Loss (CL) were measured in the muscle of different cut, meat samples were Weighed (Wi), held in plastic bags and then immersed in a water-bath at $75^{\circ} \mathrm{C}$ until the internal temperature, monitored with a thermo-couple (30 min), reached $75^{\circ} \mathrm{C}$. After cooling, the sample weights were recorded. Cooking loss was calculated using the following formula:

$$
\text { Cooking loss } \%=\left[\begin{array}{l}
(\text { Weight before cooked (Wi) }- \\
\text { Weight after cooked (Wf)) } \\
\text { Weight before cooked (Wi) }
\end{array}\right] \times 100
$$

Minerals were determined using an atomic absorption spectrophotometer (SHIMADZU A 6800, Columbia, Mayrland 21.64 and USA).

Color variables $\left(\mathrm{L}^{*}, \mathrm{a}^{*}, \mathrm{~b}^{*}\right)$ were measured in Longissimus dorsi using a Minolta CR 400 color meter calibrated to a standard white tile. $\mathrm{L}^{*}$ is the lightness and it is a measure of the reflected light $(100=$ All light reflected; 0 = All the light absorbed); ${ }^{*}$ (positive values 
red, negative values green) and $b^{*}$ (positive values yellow, negative values blue). Vitamins were determined according to the method of Albala-Hurtado et al. (1997a, b).

Fatty acids analysis of meat: Fat content was determined according to a Hara and Radin (1978) method using two solvents hexane/isopropanol mixture (3:2, v/v). Fatty Acid Methyl Esters (FAME) were obtained from meat fat with basic trans-methylation according to ISO 15884/FIL 182 methods and analyzed through GC-FID. Separation and quantification of the methyl esters were carried out using a gas chromatograph coupled to a GC-MS mass spectrometer (Shimadzu "GC-QP 2010 ultra", Japan), equipped with a split/splitless injector and a flame ionization detector. The methyl ester separation was carried with polar stationary phase (cyanopropylphenyl) using helium as the carrier gas (helium). Injections were made in split mode (1/5). The injection volume is $1 \mu \mathrm{L}$ of each sample. The identification of the fatty acids is carried out by comparing their mass spectra with the mass spectra of the reference standard fatty acid methyl esters. Individual FAMEs (Sigma-Aldrich, St. Louis, MO, USA) were identified on the basis of the retention time and the comparison with a standard (Mix, Sigma-Aldrich, Saint Louis, MO, USA).

Statistical analysis: Data were analyzed by GLM procedure with by SAS system to determine the effects of diets and different cuts on the physico-chemical parameter, vitamin and fatty acid profile of meat. Significance of difference between means was determined with Duncan test.

\section{RESULTS AND DISCUSSION}

Chemical composition: The mean $\mathrm{pH}$ value of kid's meat was similar in three diets (Table 2). The $\mathrm{pH}$ values in our study are considered high, since, they exceed the ultimate $\mathrm{pH}$ (5.8) reported by Normand (2005). The final $\mathrm{pH}$ may vary, depending on the handling and pre-slaughter diet of the animals and other factors associated with the animal such as age, temperament, species and gender (Cordova-Torresa et al., 2017). However, the change in $\mathrm{pH}$ is not homogeneous in the carcass: they differ from one muscle to another or even from one location to another in the same muscle. The mean $\mathrm{pH}$ value was varied between cuts, it's higher in neck and shoulder compare to leg and loin; there were significant difference $(\mathrm{p}<0.001)$ on different cuts (Table 2). These results are in agreement with those reported by Ben Lassoued (2010) who found that the thigh present the lowest in sheep meat race Barbarine $\mathrm{pH}$ values while those of the shoulder and breast are the highest values. Values in our study is slightly higher than those (5.69 and 5.65) found by Islam et al. (2010) for the shoulders and the legs of goats Korea. These variations between species and muscles are related to the metabolic type of muscle fibers. The ultimate $\mathrm{pH}$ value reached $5.80( \pm 0.2)$ after maturation shoulder while that it is 5.71 for the leg and 5.59 for rack meat.

The mean value of the cooking loss was similar in meat of kids for three diets (Table 2). Cooking loss which is one of the meat quality parameters, refers to the reduction in weight of meat during the cooking process (Jama et al., 2008). The percentage of cooking loss generally varies in the range $18-34 \%$ as reported by

Table 2: Chemical composition of the muscle of goat according to diet system and different cuts

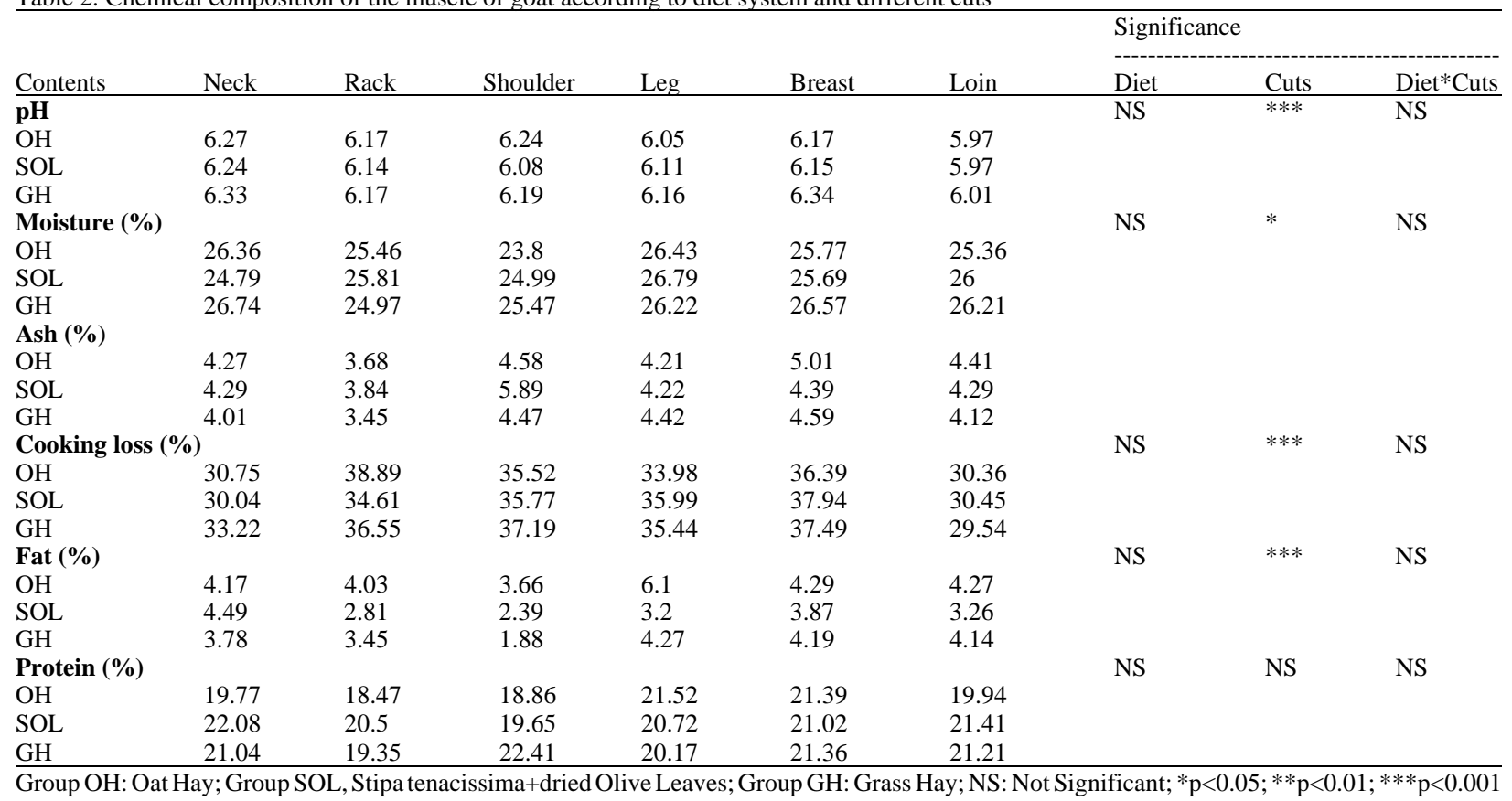


Kannan et al. (2001). The difference of value for cooking loss was highly significant between cuts; the mean value was very low in neck and loin compare to rack and breast (Table 2). Dry matter and ash content of meat were comparable between diets systems (Table 2). Likewise, dietary had no significant effect on fat content of meat in goats belonging to different diets (OH, SOL and $\mathrm{GH})$ and cuts. Dietary has a significant effect on crude protein content of meat in goats belonging to different groups and in different cut, it was higher in neck of kid's received SOL diets $(22.08 \%)$ and very lower in rack for animal received oat hay(18.47\%). Under good quality roughage and supplement concentrate diet with 15\% crude protein at different energy levels (low: 10.44 MJ ME/kg DM, medium: $11.60 \mathrm{MJ} \mathrm{ME} / \mathrm{kg} \mathrm{DM}$ and high energy: 12.90 MJ ME/kg DM) did not show any significant difference on meat (Wattanachant, 2018).

Color parameters: Color is the main factor of choice for the purchase of meat by consumers. The color parameters $\left(L^{*}, a^{*}, b^{*}\right)$ of the meat was significantly affected $(p<0.001)$ by the different cuts. The meat color of the breast was darker with brightness values $\mathrm{L}$ * was between 37 and 34 in the three diets (Table 3 ). In general, meat with a luminosity value $\left(\mathrm{L}^{*}\right)$ greater than 44 has been shown to be acceptable by $95 \%$ of consumers while a value below 34 is unacceptable (Khliji et al., 2010). In the present study, the $L^{*}$ value was greater or equal to 34 in the different cut for all diets which tends to be darker. However, shoulder meat has the highest values of a* and $\mathrm{b}^{*}$ than the other cuts. These results are in agreement with those reported by Kannan et al. (2001) who mentioned that the color of shoulder for Spanish goats is the most reddish than the other cuts. Feeding system did not affect color parameters ( $\left.L^{*}, a^{*}, b^{*}\right)$ as also observed by Hwang et al. (2018) for meat of goat finished on intensive feeding of) and Japanese alfalfa and conventional feeding of commercial concentrate pellets. In contrast, several researchers have reported that grass feeding affects several characteristics of meat quality such as color. Color is also related to the $\mathrm{pH}$ value, in our study, the $\mathrm{pH}$ was higher in meat from OL group which induces a slightly more red meat and more yellow than the other two groups. It is well known that higher $\mathrm{pH}$ values produce meat that is darker in colour. The way consumers usually associate meat colour and brightness with meat freshness according to their cultural background. Colour is the main factor that consumers use to discriminate when buying meat. For example, Spanish (Sanudo et al., 2012; Zembayashi et al., 1999) consumers prefer pale meat to dark meat, unlike the Tunisian consumers who rather like dark meat (Najari, 2005).

Water and fat soluble vitamins: The concentrations of the different vitamins studied in the 6 cuts according to the diet are presented in Table 4. Some vitamins studied were significantly affected by the type of cuts and the diet. For the rack, concentration of vitamins B1 and B12 were higher in the meat for kid's received grass hay. However, the vitamin B7 concentration was higher in the diet based on oat hay. Bauchart and et al. (2008) showed that vitamin concentration varies by muscle type.

\begin{tabular}{llll}
\multicolumn{5}{l}{ Table 3: Parameters of color in meat of different cuts and meat of 3 diets } \\
\hline Parameters & L $^{*}$ & $\mathrm{a}$ & $\mathrm{b}$ \\
\hline Cuts & & & \\
Rack & $44,86^{\mathrm{a}}$ & $8,45^{\mathrm{b}}$ & $2,48^{\mathrm{b}}$ \\
Loin & $46,65^{\mathrm{a}}$ & $18,44^{\mathrm{a}}$ & $5,58^{\mathrm{ab}}$ \\
Leg & $39,52^{\mathrm{ab}}$ & $15,13^{\mathrm{a}}$ & $4,51^{\mathrm{b}}$ \\
Breast & $35,93^{\mathrm{b}}$ & $15,94^{\mathrm{a}}$ & $4,24^{\mathrm{b}}$ \\
Shoulder & $47,34^{\mathrm{a}}$ & $19,34^{\mathrm{a}}$ & $8,17^{\mathrm{a}}$ \\
Neck & $41,11^{\mathrm{ab}}$ & $14,13^{\mathrm{b}}$ & $2,52^{\mathrm{b}}$ \\
Diets & & & \\
OH & 44.38 & 16.74 & 7.35 \\
SOL & 45.45 & 17.31 & 7.64 \\
GH & 45.85 & 16.3 & 6.94 \\
Effect & & & \\
Diets & $\mathrm{NS}$ & $\mathrm{NS}$ & NS \\
Cuts & 0 & 0 & $* * *$ \\
Diets*Cuts & $* * *$ & $\mathrm{NS}$ & $* * *$ \\
\hline
\end{tabular}

Group OH: Oat Hay; Group SOL: Stipa tenacissima+dried Olive Leaves; Group GH: Grass Hay; NS: Not Significant; *p<0.05; ${ }^{* *} \mathrm{p}<0.01 ; * * * \mathrm{p}<0.001$

Table 4: Concentration of water and fat-soluble vitamins ( $\mathrm{mg} / \mathrm{kg}$ ) in different cuts subjected to 3 diets

\begin{tabular}{|c|c|c|c|c|c|c|c|c|c|c|c|}
\hline Parameters & $\mathrm{B}_{1}$ & $\mathrm{~B}_{2}$ & $\mathrm{~B}_{3}$ & $\mathrm{~B}_{5}$ & $\mathrm{~B}_{6}$ & $\mathrm{~B}_{7}$ & $\mathrm{~B}_{12}$ & $\mathrm{~A}$ & $\mathrm{D}$ & $E$ & $\mathrm{~K}$ \\
\hline \multicolumn{12}{|l|}{ Diets } \\
\hline $\mathrm{OH}$ & $18.11^{\mathrm{b}}$ & 0.58 & 2.34 & 11.65 & 0.13 & $49.49^{\mathrm{a}}$ & $0.046^{\mathrm{ab}}$ & 0.86 & 0.006 & 0.005 & 0.021 \\
\hline SOL & $16.60^{\mathrm{b}}$ & 0.62 & 0.28 & 9.97 & 0.08 & $39.53^{\mathrm{ab}}$ & $0.030^{\mathrm{b}}$ & 0.86 & 0.007 & 0.079 & 0.077 \\
\hline GH & $23.75^{\mathrm{a}}$ & 0.41 & 3.11 & 14.15 & 0.15 & $19.33^{b}$ & $0.057^{\mathrm{a}}$ & 0.95 & na & 0.001 & 0.024 \\
\hline \multicolumn{12}{|l|}{ Cuts } \\
\hline Rack & $19.49^{\mathrm{a}}$ & 0.53 & $1.86^{\mathrm{b}}$ & $11.92^{\mathrm{ab}}$ & 0.12 & 36.12 & $0.044^{\mathrm{b}}$ & $0.89^{\mathrm{a}}$ & na & 0.028 & $0.041^{\mathrm{ab}}$ \\
\hline Loin & $22.39^{\mathrm{a}}$ & 0.44 & $15.28^{\mathrm{a}}$ & $16.35^{\mathrm{a}}$ & 0.33 & 17.37 & $0.035^{\mathrm{b}}$ & $0.90^{\mathrm{a}}$ & 0.006 & 0.015 & $0.057^{\mathrm{ab}}$ \\
\hline Leg & $0.001^{\mathrm{b}}$ & 0.42 & $0.47^{\mathrm{c}}$ & $6.08^{\mathrm{b}}$ & na & 26.91 & $0.296^{\mathrm{a}}$ & $0.12^{\mathrm{b}}$ & nd & 0.003 & $0.032^{\mathrm{b}}$ \\
\hline Breast & $0.001^{\mathrm{b}}$ & 0.59 & $3.40^{\mathrm{b}}$ & $4.52^{\mathrm{b}}$ & na & 11.74 & $0.037^{\mathrm{b}}$ & $0.90^{\mathrm{a}}$ & 0.007 & 0.021 & $0.029^{\mathrm{b}}$ \\
\hline Shoulder & $19.28^{\mathrm{a}}$ & 0.43 & $26.15^{\mathrm{a}}$ & $18.08^{\mathrm{a}}$ & 0.22 & 34.94 & $0.056^{\mathrm{b}}$ & $0.91^{\mathrm{a}}$ & 0.001 & 2.492 & $0.079^{\mathrm{a}}$ \\
\hline Neck & $22.42^{\mathrm{a}}$ & 0.49 & $26.83^{\mathrm{a}}$ & $13.43^{\mathrm{ab}}$ & 0.21 & 3.29 & na & $0.44^{\mathrm{ab}}$ & na & 0.008 & $0.013^{\mathrm{b}}$ \\
\hline \multicolumn{12}{|l|}{ Effect } \\
\hline Diet & $* * *$ & NS & NS & NS & NS & * & * & NS & NS & NS & NS \\
\hline Cuts & * & NS & $* *$ & $* * *$ & $* * *$ & NS & $* *$ & $* * *$ & NS & NS & * \\
\hline Diet*Cuts & $* * *$ & $* *$ & NS & NS & $* * *$ & NS & * & $* * *$ & NS & NS & NS \\
\hline
\end{tabular}

Group OH: Oat Hay; Group SOL: Stipa tenacissima+dried Olive Leaves; Group GH: Grass Hay; na: not available; a,b; a, b: Means followed by different letters in the same row are different; NS: Not Significant; ${ }^{*} \mathrm{p}<0.05 ;{ }^{* *} \mathrm{p}<0.01 ;{ }^{* * *} \mathrm{p}<0.001$ 
J. Anim. Vet. Adv., 18 (10): 291-297, 2019

Table 5: Mineral composition of different cuts subjected to 3 dits of kid's

\begin{tabular}{|c|c|c|}
\hline Parameters & Phosphorus & Iron \\
\hline \multicolumn{3}{|l|}{ Diets } \\
\hline $\mathrm{OH}$ & 54.57 & 1.85 \\
\hline SOL & 52.45 & 2.06 \\
\hline $\mathrm{GH}$ & 53.57 & 1.87 \\
\hline \multicolumn{3}{|l|}{ Cuts } \\
\hline Rack & $57.17^{\mathrm{a}}$ & 1.63 \\
\hline Loin & $53.88^{\mathrm{a}}$ & 2.17 \\
\hline Leg & $53.81^{\mathrm{a}}$ & 2.00 \\
\hline Breast & $44.72^{\mathrm{b}}$ & 1.87 \\
\hline Shoulder & $58.14^{\mathrm{a}}$ & 1.785 \\
\hline Neck & $52.73^{\mathrm{ab}}$ & 2.11 \\
\hline \multicolumn{3}{|l|}{ Effect } \\
\hline Diets & NS & NS \\
\hline Cuts & 0 & NS \\
\hline Diets*Cuts & $* *$ & NS \\
\hline
\end{tabular}

Table 6: Fatty acid composition (\% FAME) in meat of kids of local Tunisian goats

\begin{tabular}{|c|c|c|c|c|c|c|c|c|c|c|c|c|}
\hline Parameters & C12:0 & C14:0 & C16:0 & C18:0 & SFA & MUFA & PUFA & $\Sigma \omega 3$ & $\Sigma \omega 6$ & $\omega 6 / \omega 3$ & $\Sigma$ trans & $\mathrm{AI}$ \\
\hline \multicolumn{13}{|l|}{ Diet } \\
\hline $\mathrm{OH}$ & 0.26 & 4.27 & 13.82 & 16.30 & 42.89 & 50.75 & 6.39 & 0.47 & 5.92 & 13.57 & 1.34 & 0.55 \\
\hline SOL & 0.31 & 4.66 & 12.87 & 16.29 & 42.77 & 50.44 & 6.85 & 0.58 & 6.30 & 11.71 & 1.09 & 0.56 \\
\hline GH & 0.26 & 4.31 & 13.83 & 16.80 & 42.50 & 50.77 & 6.90 & 0.61 & 6.30 & 7.77 & 1.51 & 0.55 \\
\hline \multicolumn{13}{|l|}{ Cuts } \\
\hline Rack & 0.27 & 4.15 & 12.94 & 15.39 & 42.74 & 52.58 & $7.56^{\mathrm{ab}}$ & $0.70^{\mathrm{ab}}$ & $6.86^{\mathrm{ab}}$ & $12.50^{\mathrm{ab}}$ & 4.38 & 0.51 \\
\hline Loin & 0.29 & 4.59 & 12.94 & 17.65 & 43.07 & 51.19 & $5.87^{\mathrm{c}}$ & $0.45^{b c}$ & $5.43^{c}$ & $11.98^{\mathrm{ab}}$ & 1.08 & 0.56 \\
\hline Leg & 0.29 & 4.37 & 13.92 & 17.35 & 40.79 & 51.24 & $7.98^{\mathrm{a}}$ & $0.86^{\mathrm{a}}$ & $7.12^{\mathrm{a}}$ & $8.63^{\mathrm{b}}$ & 1.10 & 0.54 \\
\hline Breast & 0.26 & 4.11 & 14.73 & 17.11 & 44.59 & 49.31 & $6.37^{\mathrm{bc}}$ & $0.58^{\mathrm{bc}}$ & $5.80^{\mathrm{bc}}$ & $10.67^{a b}$ & 1.52 & 0.57 \\
\hline Shoulder & 0.19 & 3.67 & 16.26 & 8.97 & 42.75 & 49.65 & $7.60^{\mathrm{ab}}$ & $0.45^{\mathrm{bc}}$ & $7.15^{\mathrm{a}}$ & $17.62^{\mathrm{a}}$ & 1.59 & 0.55 \\
\hline Neck & 0.32 & 5.2 & 11.86 & 19.51 & 42.13 & 52.42 & $5.46^{c}$ & $0.32^{\mathrm{c}}$ & $5.14^{c}$ & $15.09^{\mathrm{a}}$ & 1.04 & 0.57 \\
\hline \multicolumn{13}{|l|}{ Effect } \\
\hline Diet & NS & NS & NS & NS & NS & NS & NS & NS & NS & NS & NS & NS \\
\hline Cuts & NS & NS & NS & NS & NS & NS & $* * *$ & $* *$ & $* * *$ & * & NS & NS \\
\hline Diet *cuts & NS & NS & NS & NS & NS & NS & $* *$ & 0 & $* *$ & * & NS & NS \\
\hline
\end{tabular}

MUFA: Monounsaturated Fatty Acids; PUFA: Polyunsaturated Fatty Acids; Fatty acids; $\Sigma \Sigma$ fatty acid trans C18:1t-11t. Sum of C18:1t-6 to t-16 excluded C18:1 t-11; $\Sigma$ C18:1c-9c. Sum of C18:1 CIS excluded C18:1 9c; AI: Atherogenicity Index; C12:0+4 9 C14:0+C16:0)/(MUFA+ $\omega 6+\omega 3)$; Group OH: Oat Hay; Group OL: Stipa tenacissima+dried Olive Leaves; Group GH: Grass Hay; a, b: Means followed by different letters in the same row are different NS: Not Significant; ${ }^{*} \mathrm{p}<0.05 ;{ }^{* *} \mathrm{p}<0.01 ;{ }^{* * *} \mathrm{p}<0.001$

Exception to $\mathrm{B} 2$ and $\mathrm{B} 3$, the breast was poorer in water-soluble vitamins (B1, B5, B6, B7 and B12) but leg was characterized by the lowest concentrations of fat-soluble vitamins. The vitamin D levels were very low in the differnent cutts Demeyer and Doreau (1999) that fat-soluble vitamins such as vitamins A and D are found in significant amounts only in offal including the liver. Meat is also a good source of vitamin E. The shoulder was the richest in this vitamin $\left(6.00 \mathrm{mg} \mathrm{kg}^{-1}\right)$ for kids received SOL diet.

Mineral composition: The effect of the three diets on the levels of phosphorus and iron is shown in Table 5. The feeding of the kids with oat hay resulted in richer neck meats $\left(57.20 \pm 5,45 \mathrm{mg} \mathrm{kg}^{-1}\right)$ than the other two groups (SOL and $\mathrm{OH}$ ). On the other hand, the $S$. tenacissima diet caused higher phosphorus content in the leg $\left(60.81 \mathrm{~g} \mathrm{~kg}^{-1}\right)$. While in the breast, the highest content was recorded in the grass hay based diet (58.50 $\mathrm{mg} \mathrm{kg}^{-1}$ ). For the other cuts (rack, loin and shoulder), the diet has no significant effect on phosphorus content with a slight increase in the meat of the group FA kids. The iron content was similar in the different cuts of three feed groups.

Fatty acid in meat: The diet has no significant effect on the sum of the SFA in the different cuts or diet. The lauric (C12: 0) and myristic (C14: 0) acids were slightly lower in the shoulder and breast (Table 6). The high presence of these two fatty acids and the palmitic acid (C16: 0) favoring the risk of cardiovascular diseases (Williams, 2000). They increase the plasma concentrations of LDL cholesterol. The sum of trans fatty acids was not affected by diet and cuts but the concentration of trans fatty acids (C18: 19t) was slightly lower in meat from kids received SOL diet (1.09\% FAME) and it's lower in loin compare to other cuts. The PUFA concentration was similar in the three diets and it was significantly different between the different cuts $(\mathrm{p}<0.001)$. PUFA concentration was higher in leg, shoulder and rack (7.98; 7.60 and 7.56\% 
FAME, respectively). The sum of omega 3 fatty acids composed mainly of $\alpha$-linolenic acid (C18:3$\left.\Delta^{9,12,15}\right)$ and eicosapentaenoic acid (C20:5 $\Delta^{5,8,11,14,17}$ ) was similar in three diet but it was slightly higher in rack, loin and shoulder particularly for kids received grass hay diet. Similarly, the sum of omega 6 was similar in the different diet and affected by type of cut, the high concentration of omega 6 was observed in leg and shoulder. The $\omega 6 / \omega 3$ ratio was not affected by the diet. Nutritional recommendations are to increase the level of $n 3$ fatty acids in the diet by focusing on foods with an n6/ n3 ratio not exceeding 4 (British Department of Health, 1994). In our study, meat from three groups had a greater than the recommended limit. An excessively high $\omega 6 / \omega 3$ ratio is associated with a higher risk of atherosclerosis and coronary heart disease (Geay et al., 2002). Meat from goat's kid fed with grass hay had a lower $\omega 6 / \omega 3$ ratio compared to other diet (Table 6). In particular grass hay forage, characterized by several pastoral species and was richer in polyunsaturated fatty acids and linolenic acid with respect to other feeds SOL and OH (Table 1). In the meat of the different cuts, the ratio n6/n3 is higher than the norm, this ratio remains lower in the leg (8.63) compared to other cuts. In the present study, even if the $\omega 6 / \omega 3$ ratio was high than the recommended norm, the meats of the different cuts in the three diets are characterized by low proportions of trans fatty acids with except of the rack, concentration of tran fatty acid was $<2.5 \%$ in all the cuts of 3 diets (Table 6). Epidemiological studies have reported that consumption of trans fatty acids is detrimental to human health (Mozaffarian et al., 2009). Several studies have shown that daily consumption of trans fatty acid in excess of $2 \%$ of total energy intake can increase the incidence of cardiovascular disease by $25 \%$ (Leger, 2000). The sum of trans fatty acids was slightly lower in meat of SOL group (Table 6).

\section{CONCLUSION}

The use of local forage resources in arid regions (Stipa tenacissima, olive leaves and grass hay) in feed of animal is no longer frequently used by pastoralists today. The feeding of goats by these resources have been able to improve in a variable way the vitamin contents in the different cuts and especially, for vitamin E. Thus, they were able to increase the PUFA content in the different cuts and to have lower proportions in trans FA, especially, for meat from the grass hay diet and this may be due to the high wealth of this PUFA resource.

\section{ACKNOWLEDGEMENTS}

This study was financed by the Laboratory of Livestock and Wildlife, Institute of Arid Regions (Tunisia). The researchers thank Mrs. Slah Zaidi, Mahmoud Mabrouk and Talel Bouhamda in central laboratory for the contribution to chemical analysis (vitamin and fatty acids of meat and forage).

\section{REFERENCES}

AOAC., 1990. Official Methods of Analysis. 16th Edn., AOAC., Washington, DC. USA., Pages: 1298.

Albala-Hurtado, S., M.T. Veciana-Nogues, M. Izquierdo-Pulido and A. Marine-Font, 1997a. Determination of water-soluble vitamins in infant milk by high-performance liquid chromatography. J. Chromatogr. A, 778: 247-253.

Albala-Hurtado, S., M.T. Veciana-Nogues,, M. Izquierdo-Pulido and M.C. Vidal-Carou, 1997b. Determination of free and total furfural compounds in infant milk formulas by high-performance liquid chromatography. J. Agric. Food Chem., 45: 2128-2133.

Ayeb, N., M. Hammadi, M. Addis, T. Khorchani, 2014. Chemical composition and fatty acid profiles of some local forage resources in southern Tunisia. Options Mediterraneennes, 109: 115-118.

Ayeb, N., M. Seddik, N. Atti, M. Atigui and I. Fguiri et al., 2016. Growth, feed intake and carcass characteristics of indigenous goats fed local resources in Tunisian arid land. Anim. Prod. Sci., 10.1071/AN14879

Bauchart, D., F. Chantelot and G. Gandemer, 2008. Nutritional qualities of beef meat and offal: Recent data on the main components of nutritional interest. Cah. Nutr. Dietetique, 43: 1S29-1S39.

Ben Lassoued, N., 2010. Characterization of sheep meat from different production systems in the region of Sidi Bouzid. Master Thesis, University of Carthage, Tunis, Tunisia.

British Department of Health, 1994. Nutritional aspects of cardiovascular disease. Report on Health and Social Subjects No. 46, Her Majesty's Stationery Office (HMSO), The National Archives, London, UK.

Colomer-Rocher, F., P. Morand-Fehr and A.H. Kirton, 1987. Standard methods and procedures for goat carcass evaluation, jointing and tissue separation. Livestock Prod. Sci., 17: 149-159.

Cordova-Torres, A.V., R.G. Costa, J.T.A. Filho, A.N. Medeiros and H.M. Andrade-Montemayord, 2017. Meat and milk quality of sheep and goat fed with cactus pear. J Prof. Assoc. Cactus Dev., 1: 11-31.

Demeyer, D. and M. Doreau, 1999. Targets and procedures for altering ruminant meat and milk lipids. Proc. Nutr. Soc., 58: 593-607.

Geay, Y., D. Bauchart, J.F. Hocquette and J. Culioli, 2002. [Dietary value and sensory qualities of ruminant meats (In French)]. Productions Animales, 1: 37-52.

Hara, A. and N.S. Radin, 1978. Lipid extraction of tissues with low toxicity solvent. Anal. Biochem., 90: 420-426. 
Hwang, Y.H., A. Bakhsh, I. Ismail, J.G. Lee and S.T. Joo, 2018. Effects of intensive alfalfa feeding on meat quality and fatty acid profile of Korean native black goats. Korean J. Food Sci. Anim. Resour., 38: 1092-1100.

Islam, R., S.M.E. Rahman, M. Khan, S. Akhter and M.M. Hossain et al., 2010. Quality determination of different wholesale cuts of goat carcass at different ages. J. Food Hyg. Saf., 25: 251-257.

Jama, N., V. Muchenje, M. Chimonyo, P.E. Strydom, K. Dzama and J.G. Raats, 2008. Cooking loss components of beef from Nguni, Bonsmara and Angus steers. Afr. J. Agric. Res., 3: 416-420.

Kannan, G., B. Kouakou and S. Gelaye, 2001. Color changes reflecting myoglobin and lipid oxidation in chevon cuts during refrigerated display. Small Rumin. Res., 42: 67-74.

Khliji, S., R. van de Ven, T.A. Lamb, M. Lanza and D.L. Hopkins, 2010. Relationship between consumer ranking of lamb colour and objective measures of colour. Meat Sci., 85: 224-229.

Leger, C.L., 2000. Vitamin E: Current state of knowledge, role in the prevention of cardiovascular disease, bioavailability. OCL, 7: 235-265.
Mozaffarian, D., A. Aro and W.C. Willett, 2009. Health effects of trans-fatty acids: Experimental and observational evidence. Eur. J. Clin. Nutr., 63: S5-S21.

Najari, S., 2005. Zootechnical and genetic characterization of a caprine population. Ph.D. Thesis, Case of the Local Caprine Population of the Tunisian Arid Areas.

Normand, J., 2005. Color of veal and fat cattle. International Livestock Research Institute (ILRI), Nairobi, Kenya.

Sanudo, C., M.M. Campo, E. Muela, J.L. Olleta and R. Delfa et al., 2012. Carcass characteristics and instrumental meat quality of suckling kids and lambs. Spanish J. Agric. Res., 10: 690-700.

Wattanachant, C., 2018. Goat meat: Some factors affecting fat deposition and fatty acid composition. Songklanakarin J. Sci. Technol., 40: 1152-1157.

Williams, C.M., 2000. Dietary fatty acids and human health. Ann. Zootech., 49: 165-180.

Zembayashi, M., D.K. Lunt and S.B. Smith, 1999. Dietary tea reduces the iron content of beef. Meat Sci., 53: 221-226. 